To be published in American Industrial Hygiene Association Journal

LBNL - 51010

\title{
ENVIRONMENTAL TOBACCO SMOKE LEAKAGE FROM SMOKING ROOMS
}

\author{
Wagner J. ${ }^{\text {a }}$, Sullivan D.P. ${ }^{\mathrm{b}}$, Faulkner D. ${ }^{\mathrm{b}}$, Fisk W.J. ${ }^{\mathrm{b}}$, Alevantis L.E. ${ }^{\mathrm{a}}$, Dod \\ R.L. ${ }^{\text {,c }}$, Gundel L.A. ${ }^{\mathrm{b}}$, and Waldman J.M. ${ }^{\mathrm{a}}$ \\ ${ }^{a}$ Environmental Health Laboratory \\ California Department of Health Services \\ 2151 Berkeley Way, Rm. 334 \\ Berkeley, CA 94704 \\ ${ }^{\mathrm{b}}$ Indoor Environment Department \\ Lawrence Berkeley National Laboratory, \\ 1 Cyclotron Road, Mailstop 90-3058 \\ Berkeley, CA 94720 \\ ${ }^{\mathrm{c}}$ Public Health Institute \\ 2001 Addison Street, $2^{\text {nd }}$ Floor \\ Berkeley, CA 94704
}

This work was supported by funds provided by the Cigarette and Tobacco Surtax Fund of the State of California through the Tobacco-Related Disease Research Program, Office of the President, University of California, (\#8RT-0157S), and the Assistant Secretary for Energy Efficiency and Renewable Energy, Building Technologies Program, U.S. Department of Energy under Contract No. DEAC03-76SF00098. 


\begin{abstract}
Twenty-seven laboratory experiments were conducted in a simulated smoking room to quantify rates of environmental tobacco smoke (ETS) leakage to a non-smoking area as a function of the physical and operational characteristics of the smoking room. Data are presented for the various types of leakage flows, the effect of these leaks on smoking room performance and non-smoker exposure, and the relative importance of each leakage mechanism. The results indicate that the first priority for an effective smoking room is to maintain it depressurized with respect to adjoining non-smoking areas. The amount of ETS pumped out by the smoking room door when it is opened and closed can be reduced significantly by substituting a sliding door for the standard swing-type door. An "open doorway" configuration used twice the ventilation flow as those with smoking room doors, but yielded less reduction in non-smoker exposure. Measured results correlated well with results modeled with mass-balance equations $\left(\mathrm{R}^{2}=0.82\right.$ 0.99). Most of these results are based on sulfur hexafluoride $\left(\mathrm{SF}_{6}\right)$ tracer gas leakage. Because five measured ETS tracers showed good correlation with $\mathrm{SF}_{6}$, these conclusions should apply to ETS leakage as well. Field tests of a designated smoking room in an office building qualitatively agreed with model predictions.
\end{abstract}

KEYWORDS: Environmental tobacco smoke, ventilation, indoor air quality, designated smoking rooms, exposure assessment INTRODUCTION

Exposure to environmental tobacco smoke (ETS) has been associated with several adverse health effects, including cancer of the lung and sinus ${ }^{(1)}$. As a result, many workplaces have either limited smoking to designated smoking areas or banned smoking altogether.

Liu et al. ${ }^{(2)}$ studied 23 designated smoking areas and found that their effectiveness in preventing ETS leakage varied considerably depending on their design. The most effective smoking area designs were those that had an exhaust to the outside, could maintain a negative pressure, did not recirculate air to the rest of the building, and were enclosed by true "floor-to-floor" walls. These findings imply certain leakage mechanisms in the less successful smoking areas. 
The work reported here consisted of three objectives: 1) to quantify ETS leakage flows as a function of various operating and design parameters in a controlled chamber, 2) to measure the impact of these mechanisms on smoking room performance, and 3) to develop a smoking room performance model and test it both in the chamber and in a real-world smoking room. All three objectives were achieved primarily by measuring the leakage of a sulfur hexafluoride $\left(\mathrm{SF}_{6}\right)$ tracer gas that had been released in a manner that simulated ETS generation. In some cases, however, the dynamics and transport of the various ETS components can differ substantially from that of $\mathrm{SF}_{6}{ }^{(3)}$ and from each other ${ }^{(4)}$. To address this issue, five particle- and gas-phase ETS tracers were measured in a subset of the chamber tests and all field tests.

Three potential ETS leakage mechanisms were investigated in the chamber tests: (a) through the gap under the door and wall cracks when the smoking room is pressurized relative to the non-smoking area; (b) via the pumping action of the door as occupants enter and exit the smoking room; and (c) through the ceiling plenum. If the ceiling plenum above the smoking room is not isolated from the adjoining space's plenum, ETS can leak into the shared plenum, where it can be recirculated into non-smoking areas. Even if the smoking room is depressurized relative to the ceiling plenum, whenever the door opens, the smoking room pressure will quickly equilibrate with that of the non-smoking area and become higher than that of the plenum. This situation can result in sporadic bursts of ETS into the ceiling plenum.

The impact of these leakage mechanisms on smoking room effectiveness was assessed using two performance measures, the smoking room exhaust efficiency and the ETS reduction factor. The smoking room exhaust efficiency is the percentage of smoking room ETS that is successfully removed by the exhaust to the outdoors. ETS that is not removed in this way is available for sorbing to smoking room surfaces and leaking into adjoining, non-smoking areas. The steady-state exhaust efficiency, $\eta_{\text {exh, }}$ is given by

$$
\eta_{\mathrm{exh}}=\mathrm{Q}_{\mathrm{exh}, \mathrm{SR}}[\mathrm{ETS}]_{\mathrm{SR}} / \mathrm{S} \quad \mathrm{x} \quad 100 \%
$$

where $Q_{\text {exh, SR }}$ is the smoking room exhaust flow, $[\mathrm{ETS}]_{\mathrm{SR}}$ is the ETS

concentration in the smoking room exhaust duct at steady-state, and $\mathrm{S}$ is the generation rate of ETS.

We have devised a new parameter, the ETS reduction factor $\left(\mathrm{R}_{\mathrm{ETS}}\right)$. $\mathrm{R}_{\mathrm{ETS}}$ represents the reduction in ETS concentration in non-smoking areas relative to the hypothetical case with no smoking room protection:

$$
\mathrm{R}_{\mathrm{ETS}}=[\mathrm{ETS}]_{\mathrm{NSR}, \text { no SR }} /[\mathrm{ETS}]_{\mathrm{NSR}}=\left(\mathrm{S} / \mathrm{Q}_{\text {out, NSR }}\right) /[\mathrm{ETS}]_{\mathrm{NSR}},
$$


where $[\mathrm{ETS}]_{\mathrm{NSR}}$ is the measured non-smoking room ETS exposure when a smoking room is used, $[\text { ETS }]_{\mathrm{NSR}}$, no SR is the non-smoker ETS exposure that would have resulted without a separate smoking room (i.e., smoking in the same space as the non-smokers), and Qout, NSR is the total flow out of the non-smoking area. For example, an $\mathrm{R}_{\text {ETS }}$ value of 20 means that ETS exposures in the non-smoking area are 20 times lower than they would have been if the smoking room had not been in operation. In other words, the non-smoker exposure is $5 \%(=1 / 20)$ of the level that would have occurred with no smoking room. [ $\left.\mathrm{SF}_{6}\right]$ was used in place of [ETS] in Equations 1 and 2 because its injection rate $S$ was easily obtained.

Three particle-phase ETS tracers were measured: total particulate matter (PM) concentration, PM-bound scopoletin concentration, and optical absorption of PM at 370nm (UVPM). Both scopoletin and UVPM have been found to be sensitive and unique tracers of ETS ${ }^{(4,5)}$. Two gas-phase ETS tracers were measured: nicotine and 3-ethenylpyridine (3-EP).

\section{TEST CHAMBER}

An existing chamber at Lawrence Berkeley National Laboratory (LBNL) was modified so that it consisted of two rooms separated by a wall with a standard, swing-type door measuring $2.1 \times 0.89 \mathrm{~m}$ (Figure 1). The two rooms were designated the smoking room (SR) and non-smoking room (NSR), respectively. Each measured $2.2 \mathrm{~m} \times 4.6 \mathrm{~m} \times 2.4 \mathrm{~m}$, with volumes of $24.7 \mathrm{~m}^{3}$. The door opened out of the SR and the gap under the door was $0.64 \mathrm{~cm}$. A suspended ceiling created a shared, $22.9 \mathrm{~cm}$-high plenum above both rooms. The ceiling panels were of the common, "slag wool" (synthetic vitreous fiber) variety, and were cut to fit the lattice so that no gaps were visible. For the experiments with no shared plenum, the ceiling panels were removed and the plenum spaces above the two rooms were separated with a silicone-rubber-sealed acrylic divider.

Each room had a separate HVAC system and two rotating mixing fans. The supply air for each room passed through a high-efficiency filter, chiller coil, temperature-controlled duct heater, and a diffuser grille. The NSR HVAC system had a plenum return and partially-recirculated air. The SR HVAC system was a $100 \%$ outside air unit with ducted exhaust. By adjusting the recirculation, supply, and return flows with regulating valves, a wide variety of pressure differentials could be created between the SR, NSR, and ceiling plenum.

The SR was equipped with an automated, programmable smoking machine built at LBNL. The smoking machine could smoke 16 cigarettes consecutively. One cigarette was smoked at a time. A computer system controlled the smoking machine and a pneumatic-piston-based door-opening mechanism. A door "open/close" cycle was initiated immediately before a cigarette was smoked and immediately afterwards, simulating a smoker entering 
and leaving the SR. The computer shut off the mixing fans during each door cycle to prevent blowing air through the open door. $\mathrm{SF}_{6}$ was released near the smoking machine using a cylinder of $1 \% \mathrm{SF}_{6}$ and a mass flow controller set to $27.7 \mathrm{cc} / \mathrm{min}$. Typically, $\left[\mathrm{SF}_{6}\right]_{\mathrm{SR}}=100-150 \mathrm{ppb}$ at steady state.

Duct air flow rates, temperatures, and pressures were monitored using calibrated sensors and a data acquisition system. $\mathrm{SF}_{6}$ and UVPM were both monitored in near real-time. $\mathrm{SF}_{6}$ was measured at 9 locations in the 2 rooms using 2 gas chromatographs with electron capture detectors (Model 5890A, Hewlett-Packard [now Agilent Technologies], Palo Alto, CA; and Model 215BGC, Lagus Applied Technology, San Diego, CA) and automated, multiport samplers. Both instruments were calibrated before each test with the same calibration bags. UVPM concentrations in the NSR and NSR supply air were measured using two dual-wavelength Aethalometers (Model AE-21, Magee Scientific, Berkeley, CA) running at $1.7 \mathrm{~L} / \mathrm{min}$. No attempt was made to validate the manufacturer's calibration of the Aethalometer.

PM, scopoletin, nicotine, and 3-EP measurements were taken in two locations in each room. PM concentrations were determined gravimetrically using 47mm TFE-coated glass fiber filters (Pallflex Fiberfilm, Pall Gelman Laboratory, Ann Arbor, MI) in open-faced, aluminum filter cassettes (Pall Gelman Laboratory, Ann Arbor, MI). Sampling flows were $10 \mathrm{~L} / \mathrm{min}$ in the SR and 55-175 L/min in the NSR, where lower ETS concentrations were expected.

Scopoletin was quantified using a new high-performance liquid chromatography (HPLC) technique. Methanol extracts from the PM filters were concentrated down to $1 \mathrm{~mL}$ and injected into a HP Model 1090 with two HP Model 1046A fluorescence detectors (Hewlett-Packard [now Agilent Technologies], Palo Alto, CA). The scopoletin peak was resolved from the other fluorescing particulate-phase ETS components using a reverse-phase $\mathrm{C} 18$ column and gradient elution. The 12 minute program for "Solvent A" (100\% acetonitrile) and "Solvent B" (80\% distilled DI H2O /20\% acetonitrile) was as follows: $100 \%$ Solvent B for 2 minutes, linear gradient to $80 \%$ Solvent A / 20\% Solvent B for 2 minutes, hold for 4 minutes, linear gradient to $100 \%$ Solvent $\mathrm{B}$ for 2 minutes, and hold for the last 2 minutes. Solvent flow was $0.3 \mathrm{~mL} / \mathrm{min}$ and oven temp was $30^{\circ} \mathrm{C}$. The two fluorescence detectors (excitation $=225 \mathrm{~nm}$, emission $=415-\mathrm{nm}$ for both) were used in series with different photomultiplier gain settings to simultaneously measure low- and high-concentration samples.

Nicotine and 3-EP concentrations were measured using XAD-4 sorbent tubes (Catalog \#226-93, SKC Inc., Eighty Four, PA) at $1.5 \mathrm{~L} / \mathrm{min}$ and ASTM Method \#D 5075-96 ${ }^{(6)}$.

\section{CHAMBER EXPERIMENTS}


Unless noted otherwise, each test typically lasted 4.5 hours, with 1.5 hours allowed for achieving steady-state chamber concentrations. The real-time samplers were used over the entire 4.5 hours; all other samplers were operated for the last 3 hours of steady-state conditions only. Smoking room leakage flows were determined for each chamber configuration using $\mathrm{SF}_{6}$ mass balances. Four sets of experiments were performed:

1) Leakage under closed door. These tests were conducted with the door closed and no shared ceiling plenum. Three positive values of the pressure gradient between SR and NSR were investigated, $\Delta \mathrm{P}_{\mathrm{SR}}=\mathrm{P}_{\mathrm{SR}}-\mathrm{P}_{\mathrm{NSR}}=0,2.5$, and $5 \mathrm{~Pa}$. The tests were performed with $\mathrm{SF}_{6}$ only (no smoking).

The airflow under the SR door was calculated using

$$
\text { Qunder door }=\left[\mathrm{SF}_{6}\right]_{\mathrm{NSR}} \mathrm{Q}_{\text {out,NSR }} /\left[\mathrm{SF}_{6}\right]_{\mathrm{SR}},
$$

where Q Qut, NSR is the flow in the NSR exhaust duct.

2) Leakage via door pumping. These experiments lasted less than an hour and did not use a shared ceiling plenum. The gap under the door was sealed, the ventilation system was turned off, and $\Delta \mathrm{P}_{\mathrm{SR}}=0$. These tests were performed with $\mathrm{SF}_{6}$ only (no smoking). In each test, $\mathrm{SF}_{6}$ was allowed to build up in the $\mathrm{SR}$ with the door closed. After the $\mathrm{SF}_{6}$ injector was turned off, one door open/close cycle was performed, causing a burst of $\mathrm{SF}_{6}$ to be pumped into the NSR. Tests were conducted using three different temperature gradients between rooms, $\Delta \mathrm{T}_{\mathrm{SR}}=\mathrm{T}_{\mathrm{SR}}-\mathrm{T}_{\mathrm{NSR}}=2,0$, and $-2{ }^{\circ} \mathrm{C}$.

The volume of SR air pumped by one door cycle was calculated using

$$
\mathrm{V}_{\text {door pump }}=\frac{\mathrm{V}_{\mathrm{NSR}}\left(\left[\mathrm{SF}_{6}\right]_{\mathrm{NSR}, \text { after cycle }}-\left[\mathrm{SF}_{6}\right]_{\mathrm{NSR}, \text { before cycle }}\right)}{\left[\mathrm{SF}_{6}\right]_{\mathrm{SR}, \text { before cycle }}}
$$

where $\mathrm{V}_{\mathrm{NSR}}$ is the volume of the NSR, $\left[\mathrm{SF}_{6}\right]_{\mathrm{NSR}}$, after cycle is the $\mathrm{SF}_{6}$ concentration in the NSR after the door cycle, and $\left[\mathrm{SF}_{6}\right]_{\mathrm{SR}}$, before cycle is the $\mathrm{SF}_{6}$ concentration in the SR before the door cycle. In addition to the three tests with the swing-type door, one test was performed with a sliding door.

3) Leakage under door and via door pumping. In these tests, a swing-type door was opened on a regular schedule but was closed the remainder of the time, so ETS could leak both under the door and via door pumping. The major variable of these tests was $\Delta \mathrm{P}_{\mathrm{SR}}$, which varied between -10 to $+5 \mathrm{~Pa}$. These tests were performed using two different door-opening rates: 8 and 13.3 door cycles per hour (corresponding to 4 and 6.67 cigarettes per hour). In addition, two different $\Delta \mathrm{T}_{\mathrm{SR}}$ values were investigated: $0{ }^{\circ} \mathrm{C}$ and $2{ }^{\circ} \mathrm{C}$.

4) Leakage through a shared ceiling plenum. These tests were performed with 
ceiling panels in place, the ceiling plenum open between the SR and NSR, and a slightly negative $\Delta \mathrm{P}_{\mathrm{SR}}$. All but one of these tests (in which the door opened 8 times/hour) was performed with the door closed. Cigarettes were smoked during only some of these tests. Four positive values of pressure difference between $\mathrm{SR}$ and ceiling plenum were investigated, $\Delta \mathrm{P}_{\mathrm{cp}}=\mathrm{P}_{\mathrm{SR}}-\mathrm{P}_{\mathrm{cp}}$ $=0,0.3,0.8$, and $2 \mathrm{~Pa}$. In addition, the effect of varying the $\mathrm{SR}$ exhaust airflow at a constant $\Delta \mathrm{P}_{\mathrm{cp}}(0.8 \mathrm{~Pa})$ was studied. Next, two different return grille types were inserted into the suspended ceiling above the SR to determine the effect they would have on air transport into the plenum. (Despite the potential for leakage, disconnected return grilles are sometimes present in the ceilings above smoking rooms.) The flow of SR air into the ceiling plenum was calculated using

$\mathrm{Q}_{\mathrm{SR}-\mathrm{cp}}=\frac{\left[\mathrm{SF}_{6}\right]_{\mathrm{cp}}\left(\mathrm{Q}_{\mathrm{exh}, \mathrm{NSR}}+\mathrm{Q}_{\mathrm{pm}, \mathrm{cp}}\right)+\left[\mathrm{SF}_{6}\right]_{\mathrm{NSR}}\left(\mathrm{Q}_{\mathrm{pm}, \mathrm{NSR}}+\mathrm{Q}_{\text {under door }}+\mathrm{Q}_{\mathrm{NSR} \text { cracks }}\right)}{\left[\mathrm{SF}_{6}\right]_{\mathrm{SR}}}$,

where $\left[\mathrm{SF}_{6}\right]_{\mathrm{cp}}$ is the $\mathrm{SF}_{6}$ concentration in the ceiling plenum, $\mathrm{Q}_{\mathrm{pm}, \mathrm{cp}}$ and $\mathrm{Q}_{\mathrm{pm}}$, NSR are the flows of the particle-sampling pumps in the ceiling plenum and NSR, respectively, $Q_{\text {NSR cracks }}$ is the leak flow through cracks in the NSR walls to the outside, and the SR was assumed to be slightly depressurized. One additional test was performed to investigate, within the limits of the test facility, the performance of a smoking room with a fixed, open doorway and high ventilation. The flow through the doorway was $100 \mathrm{~L} / \mathrm{s}$ and the face velocity was $0.05 \mathrm{~m} / \mathrm{s}$.

In all, 27 experiments plus 5 replicates were performed. Cigarettes were smoked and ETS tracers were sampled in 9 of these tests plus 2 of the duplicates. Except for the "open doorway" test, all ventilation flow rates ranged from 0-54 $\mathrm{L} / \mathrm{s}$, corresponding to a ventilation range of 0-7.9 ACH and 0-5.3 $\mathrm{L} / \mathrm{s} /\left(\mathrm{m}^{2}\right.$ floor area). Room temperatures ranged from $23-25^{\circ} \mathrm{C}$. Well-mixed conditions were observed for both the SR and NSR in all experiments. In all experiments, UVPM levels in the supply air were negligible.

\section{REAL-WORLD SMOKING ROOM FIELD TEST}

Measurements were performed on three consecutive days in a SR on the top floor of a five-story office building in southern California. The building's outside air supply fans and recirculating units shut off every day between $8 \mathrm{pm}$ and $6 \mathrm{am}$. The SR had a ducted exhaust and a door that opened into the SR, with a gap under the door of $1.3 \mathrm{~cm}$.

Pure $\mathrm{SF}_{6}$ was injected at $1.5-2.3 \mathrm{cc} / \mathrm{min}$ into the $\mathrm{SR}$. Qunder door was determined as a function of $\Delta \mathrm{P}_{\mathrm{SR}}$ by measuring the balance of SR exhaust and 
supply flows with the door closed. $\Delta \mathrm{P}_{\mathrm{SR}}$ was monitored with a datalogger, yielding a series of pressure bursts that served as a record of entry/exits from the SR. A perfluorocarbon tracer (PFT) method utilizing perfluoromethylcyclohexane $(\mathrm{PMCH})$ was used to measure the ventilation rate in the nonsmoking area ${ }^{(7)}$. $\mathrm{SF}_{6}, \mathrm{PMCH}, \mathrm{PM} 2.5$, UVPM, nicotine, 3-EP, and scopoletin were measured from $12 \mathrm{pm}-5 \mathrm{pm}$ each day. $\mathrm{SF}_{6}$ and $\mathrm{PMCH}$ were sampled with custom-built, programmable bag samplers at 15 locations and were analyzed by GC. The others were measured in 5 locations. PM2.5 was sampled with $47 \mathrm{~mm}$ filter pack/cyclones with a $2.5 \mu \mathrm{m}$ size cut at $16.7 \mathrm{~L} / \mathrm{min}$ (URG-2000-30EH, URG, Chapel Hill, NC); the others were sampled as in the chamber.

\section{RESULTS}

\section{Chamber Tests}

Smoking room leakage flows were determined for each experiment set using $\mathrm{SF}_{6}$ mass balances. A least squares fit to the data from Experiment Set 1 produced the equation

$$
\mathrm{Q}_{\text {under door }}=6.10\left(\Delta \mathrm{P}_{\mathrm{SR}}\right)^{0.573}=1100 \mathrm{~A}_{\text {gap }}\left(\Delta \mathrm{P}_{\mathrm{SR}}\right)^{0.573}
$$

where $\mathrm{Q}_{\text {under door }}$ is in units of $\mathrm{L} / \mathrm{s}, \Delta \mathrm{P}_{\mathrm{SR}}$ is in $\mathrm{Pa}$, and the cross-sectional area of the gap under the door, $\mathrm{A}_{\text {gap }}$, is in $\mathrm{m}^{2}$.

The average $\mathrm{V}_{\text {door pump }}$ for the three swing-type-door tests in Experiment 2 was $672 \mathrm{~L}$, with no apparent dependence on $\Delta \mathrm{T}_{\mathrm{SR}}$. For the sliding door, $\mathrm{V}_{\text {door pump }}$ $=152 \mathrm{~L}$. The equivalent $\mathrm{Q}_{\text {door pump }}$ is then

$$
\mathrm{Q}_{\text {door pump }}=\mathrm{D} \mathrm{V}_{\text {door pump }},
$$

where $\mathrm{D}=$ (number of door cycles / time).

A least squares fit to the data from Experiment Set 4 yields the equation

$$
\mathrm{Q}_{\mathrm{SR}-\mathrm{cp}}=28.5\left(\Delta \mathrm{P}_{\mathrm{cp}}\right)^{0.484}
$$

where $\mathrm{Q}_{\mathrm{SR}-\mathrm{cp}}$ is in units of $\mathrm{L} / \mathrm{s}$ and $\Delta \mathrm{P}_{\mathrm{cp}}$ is in $\mathrm{Pa}$. In cases where the $\mathrm{SR}$ becomes pressurized with respect to plenum only when the door opens, the effective leak flow is then

$$
\mathrm{Q}_{\mathrm{SR}-\mathrm{cp}, \text { open door only }}=\mathrm{D} \tau_{\text {door }} \mathrm{Q}_{\mathrm{SR}-\mathrm{cp}}
$$


where $\tau_{\text {door }}$ is the average time the door is open per cycle.

The leakage flows calculated with Equations 6 - 9 are plotted together on Figure 2 as a function of the appropriate pressure drop. The plot assumes a swing-type door, $\mathrm{D}=8$ door cycles/hour, and $8 \mathrm{~s}$ /door opening. Assuming that $\Delta \mathrm{P}_{\mathrm{SR}}$ and $\Delta \mathrm{P}_{\mathrm{cp}}$ typically range within the same order of magnitude as each other, Figure 2 can be used to determine the most important leakage mechanism in a given situation.

Steady-state values of $\eta_{\text {exh }}$ and $R_{\text {ETS }}$ were determined using Equations 1 and 2 . Figure 3 shows the $\eta_{\text {exh }}$ and $R_{\text {ETS }}$ values determined in Experiment Set 3 plotted as a function of $\Delta \mathrm{P}_{\mathrm{SR}}$. Curves are plotted for $\Delta \mathrm{T}_{\mathrm{SR}}=0$ and 8 door cycles per hour, $\Delta \mathrm{T}_{\mathrm{SR}}=2{ }^{\circ} \mathrm{C}$ and 8 door cycles per hour, and $\Delta \mathrm{T}_{\mathrm{SR}}=0$ and 13.3 door cycles per hour. The $\eta_{\text {exh }}$ and $\mathrm{R}_{\text {ETS }}$ curves in Figure 3 correspond to a SR exhaust rate of $26.5 \mathrm{~L} / \mathrm{s}$.

Agreement between duplicate tests was good. For the four pairs of duplicate tests run with ventilation, the average percent difference in $\eta_{\text {exh }}$ and $\mathrm{R}_{\mathrm{ETS}}$ was $<1 \%$ and $5.2 \%$, respectively. For the fifth test pair from Experiment Set 2 , the percent difference in $\mathrm{V}_{\text {door pump }}$ was $7.8 \%$.

Mass balance calculations were performed on the various experimental configurations to model $\eta_{\text {exh }}$ and $R_{\text {ETS }}$ as a function of the chamber pressures and exhaust flows (interested readers should contact the authors for these equations and their derivations). Experiments from Experiment Set 2, those with added grilles in the ceiling, the "open doorway" test, and the test with shared plenum and 8 door cycles/hr were not modeled. The modeled $\eta_{\text {exh }}$ and $\mathrm{R}_{\text {ETS }}$ values are plotted versus the measured values in Figure 4. Very good agreement was observed, with $\mathrm{R}^{2}=0.99$ and 0.82 for $\eta_{\text {exh }}$ and $R_{E T S}$, respectively.

The range of values measured for the five ETS tracers are presented in Table 1. Correlation between $\mathrm{SF}_{6}$ and the ETS tracers was very good in the NSR (Table 2), but generally poor in the SR, especially for nicotine and 3-EP. High nicotine and 3-EP levels in the SR likely caused significant sorption onto SR walls. Re-emission of these compounds on subsequent experiment days probably led to elevated air concentrations, even during experiments when $\mathrm{PM}$ and $\mathrm{SF}_{6}$ emissions were low.

Exposure ratios $\left(=[\mathrm{ETS}]_{\mathrm{NSR}} /[\mathrm{ETS}]_{\mathrm{SR}}\right)$ were calculated for each tracer. ${ }^{(3)}$ These ratios showed good correlation $\left(\right.$ all $\left.\mathrm{R}^{2}>0.77\right)$ (Table 2$)$. However, all ETS tracers exhibited lower exposure ratios than $\mathrm{SF}_{6}$ (Figure 5), implying lower leakage to NSR air. Reduced PM exposure ratios may be partially due to differing semivolatile particle evaporation rates from the SR and NSR filters, which used much different sampling flow rates. Low nicotine exposure ratios are likely due to sorption of nicotine onto SR and NSR surfaces. The higher 3-EP exposure ratios are consistent with this interpretation, as 3-EP is more volatile and less sorptive than nicotine. 
The Aethalometer responded consistently and quickly to ETS leakage into the non-smoking room. However, the UVPM signal tended to drift slightly downward during steady-state conditions, possibly due to evaporation of semivolatile ETS components from the Aethalometer filter tape.

\section{Field Test}

Qexh, SR and Q Qut, NSR were 180 and $990 \mathrm{~L} / \mathrm{s}$, respectively, with the exception of the first experiment day, in which building management reported ventilation system problems and $\mathrm{Q}_{\text {out, }}$ NSR dropped to $690 \mathrm{~L} / \mathrm{s}$. The SR door opening rate ranged from 12-16 door cycles/hour.

The ranges of values measured for the four ETS tracers are presented in

Table 1. The nicotine levels found in the SR and NSR are comparable to previous investigators' measurements in office building spaces occupied by smokers and non-smokers ${ }^{(8,9,10)}$. Calculated correlations between PM2.5, scopoletin, nicotine, and 3-EP were extremely high $\left(\mathrm{R}^{2}>0.99\right)$. Measured $\mathrm{SF}_{6}$, scopoletin, and nicotine exposure ratios were all $<1 \%$, implying minimal ETS leakage from the SR. The PM2.5 exposure ratio was $10 \%$, but [PM2.5 $]_{\mathrm{NSR}}$ was probably dominated by non-ETS background PM. [3-EP $]_{\mathrm{NSR}}$ and $[\mathrm{UVPM}]_{\mathrm{NSR}}$ were indistinguishable from zero.

Model predictions for $\eta_{\text {exh }}$ and $R_{\text {ETS }}$ on each day of the field test were made using mass balance equations, $Q_{\text {under door }}$ (determined with Equation 10 and the measured $\Delta \mathrm{P}_{\mathrm{SR}}$ values), and $\mathrm{Q}_{\text {door pump }}$ (determined using Equation 7, the measured door-opening rates, and $\mathrm{V}_{\text {door pump }}=672 \mathrm{~L}$ ) (Table 3). Unfortunately, all $\eta_{\text {exh }}$ and $R_{\text {ETS }}$ measurements had to be discarded, as the $\mathrm{SF}_{6}$ regulator was determined to have leaked at a rate that was somewhat uncertain and much higher than the nominal rate. However, the extremely high level of smoking room performance predicted with the model is consistent with the very low levels of ETS and $\mathrm{SF}_{6}$ measured in the non-smoking area.

\section{DISCUSSION}

\section{Leakage Flows}

Equations $6-9$ are useful for predicting smoking room leakage flows in actual buildings, as the inputs are relatively easy to obtain. The $\Delta \mathrm{P}$ exponents in Equations 6 and 8 are both nearly equal to 0.5 , which agrees well with the standard relationship for flow through an orifice. It should be noted, however, that Equations 6-9 would have different coefficients for smoking room doors and ceiling panel configurations substantially different than the ones tested. For example, the disconnected grilles inserted into the suspended ceiling above the 
smoking room each increased the leakage area substantially, reduced the pressure drop across the ceiling, and increased the leakage flow. A suspended ceiling with several panels missing would likely have a very low pressure drop across the ceiling, but a substantially higher leakage flow than that predicted by Equation 8 .

Figure 2 shows that a first priority for an effective smoking room is depressurization. If this goal is achieved, the left side of the plot reveals that the most significant leakage source is the pumping action when the door opens. This leakage source may have an enhanced impact on occupants of spaces immediately adjacent to the smoking room. The $\mathrm{V}_{\text {door pump }}$ measured here for the standard door was $38 \%$ of the volume swept by door as it opened and closed. This value compares reasonably well the work of Kiel and Wilson ${ }^{(11)}$, who reported typical values of about $50 \%$. Substituting a sliding door is a promising method to reduce this leakage mechanism, as our sliding door reduced SR leakage by $77 \%$. Using a smoking room with a fixed, open doorway is a way to completely eliminate ETS leakage via door pumping. However, thermally-induced circulations across the doorway can cause ETS to leak into the non-smoking room, even when the net flow across the doorway is towards the smoking room. In our "open doorway" test, a high smoking room ventilation rate resulted in a high exhaust efficiency $(98 \%)$, but ETS levels were not much lower in the non-smoking area than they

were in the smoking room $\left(\mathrm{R}_{\mathrm{ETS}}=2.4\right)$. In contrast, $\mathrm{R}_{\mathrm{ETS}}=19-20$ for experiments with half the exhaust flow and a smoking room door. Thus, using a door was a more efficient way to control ETS leakage. Open doorways with higher face velocities than ours may be more protective, though they presumably would require even larger ventilation systems.

\section{Effect of Leakage on Smoking Room Performance}

Figure 3 shows that both $\eta_{\text {exh }}$ and $R_{\text {ETS }}$ were generally high when the smoking room was depressurized relative to the NSR, but decreased sharply as it became pressurized. From the figure, it appears that a $\Delta \mathrm{P}_{\mathrm{SR}}$ of -5 to $-7 \mathrm{~Pa}$ is necessary for an exhaust efficiency of $90 \%$. Figure 3 also reveals that a temperature difference of $2^{\circ} \mathrm{C}$ did not produce a measurable effect. Increasing the number of door cycles per hour did decrease $\eta_{\text {exh }}$ and $R_{E T S}$, but only when the SR was depressurized and door pumping was the dominant mechanism. Experiment Set 4 results showed similar trends, with $\eta_{\text {exh }}$ and $R_{\text {ETS }}$ decreasing as the SR became more pressurized with respect to the plenum.

Increasing the smoking room exhaust flow rate was found to improve both $\eta_{\text {exh }}$ and $R_{\text {ETS }}$. Although increased smoking room exhaust flow does not prevent the various ETS leakage mechanisms from occurring, it does lower the ETS concentration in the SR, effectively reducing the strength of the leakage source. A high $\eta_{\text {exh }}(91 \%)$ and $R_{\text {ETS }}(19)$ were observed for the case where leakage 
into the plenum occurs only during door openings. These results (along with Figure 2) suggest that this mechanism is relatively unimportant.

Although Q Qut, NSR is present in the numerator of Equation 2, it is also present in the denominator (implicitly in $[\mathrm{ETS}]_{\mathrm{NSR}}$ ), so its effect is minimal. Mass-balance equations show that $\eta_{\text {exh }}$ and $R_{\text {ETS }}$ are independent of $Q_{\text {out,NSR }}$ whenever $\mathrm{Q}_{\text {out, NSR }}>>\mathrm{Q}_{\text {under door }}$. This is true in almost all cases. Thus, these results can be generalized to different building sizes and non-smoking-area ventilation rates.

\section{CONCLUSION}

ETS leakage flows have been quantified as a function of various operating and design parameters in a controlled chamber. The results indicate that the first priority for an effective smoking room is to maintain it depressurized with respect to adjoining non-smoking areas. If this goal is achieved, the next most significant ETS leakage mechanism is the pumping action of the smoking room door when it is opened and closed. Substituting a sliding door for a swing-type door reduced this mechanism by $77 \%$. An "open doorway" configuration used twice the ventilation flow as those with smoking room doors, but yielded less reduction in non-smoker exposure.

Measured results correlated well with results modeled with leakage flows and simple mass-balance equations $\left(\mathrm{R}^{2}=0.82-0.99\right)$.

The relative importance of the various leakage mechanisms was determined with $\mathrm{SF}_{6}$. Because $\mathrm{SF}_{6}$ and ETS tracer exposure ratios were well correlated $\left(\mathrm{R}^{2}>0.77\right)$, these conclusions should apply to leakage of the ETS tracers as well. However, the absolute magnitudes of all leakage mechanisms and exhaust efficiencies would be somewhat less for 3-EP, scopoletin, and PM, and substantially less for nicotine.

A field test of a real-world designated smoking room was performed to compare to model calculations. Due to a leaky $\mathrm{SF}_{6}$ regulator, quantitative validation was not possible, but the high level of smoking room performance predicted by the model was qualitatively observed in the $\mathrm{SF}_{6}$ and ETS tracer data.

This information can provide guidance for effective design and operation of smoking rooms, as well as any space in which containment is required, e.g., in process, laboratory, or medical environments. The leakage flows obtained here will be used in subsequent parametric modeling studies of smoking room performance. The resulting models will be tested against additional data from actual workplace smoking rooms.

\section{ACKNOWLEDGEMENT}


The authors wish to thank Lawrence Schoen for his helpful comments, and William Wehrmeister and Marion Russell for analyzing samples.

\section{REFERENCES}

1. California Environmental Protection Agency (1997) Health effects of exposure to environmental tobacco smoke, California Environmental Protection Agency, Sacramento, CA.

2. Liu K.-S., Alevantis L.E., and Offerman F.J. (2001) A survey of environmental tobacco smoke controls in California office buildings. Indoor Air 11:2634.

3. Alevantis L.E., Liu K.-S., Hayward S.B., Shah K.B., Offerman F.J., and Leierson K. (1994) Effectiveness of ventilation in 23 designated smoking areas in California office buildings. In: Proceedings of the American Society of Heating, Refrigerating, and Air Conditioning Engineers IAQ'94 Conf., pp. 89-103.

4. Daisey J.M. (1999) Tracers for assessing exposure to environmental tobacco smoke: what are they tracing? Environ Health Perspect 107(s2):319-327.

5. Gundel L.A., Shpilberg V.E., Sullivan D., Apte M.G., Wagner J., Fisk W.J., Waldman J., and Alevantis L. (2000) Real-time monitoring of dilute environmental tobacco smoke in the presence of other particle sources. Presented at 10th Annual Conference of the International Society of Exposure Analysis, Monterey Peninsula, California.

6. ASTM, 1998. D5075-96, Standard test method for nicotine and 3ethenylpyridine in indoor air, Annual Book of ASTM Standards, West Conshohocken, PA: American Society for Testing and Materials, Vol.11.03, pp. 398-405.

7. Faulkner, D., W.J. Fisk, D.P. Sullivan, and J.M. Thomas Jr., "Characterizing Building Ventilation with the Pollutant Concentration Index: Results from Field Studies," Proceedings of IAQ \& Energy 98: Using ASHRAE Standards 62 and 90.1. 1997. LBNL-40223.

8. Vaughan W.M. and Hammond S.K. (1990) Impact of "designated smoking area" policy on nicotine vapor and particle concentrations in a modern office building. J. Air Waste Manage. Assoc. 40:1012-1017.

9. Rapace J.L., Jinot J., Bayard S., Emmons K., and Hammond S.K. (1998) Air nicotine and saliva cotinine as indicators of workplace passive smoking exposure and risk. Risk Analysis 18:71-83.

10. Hammond S.K., Leaderer B.P., Roche A., and Schenker M. (1987) Collection and analysis of nicotine as a marker for environmental tobacco smoke. Atmospheric Environment 21:457-62.

11. Kiel D.E. and Wilson D.J. (1989) Combining door swing pumping with density driven flow. ASHRAE Trans. 95:590-599. 
Table 1. Range of values measured for ETS tracers (in $\mu \mathrm{g} / \mathrm{m}^{3}$ ) for the chamber experiments and field test.

\begin{tabular}{c|cc}
\hline \multicolumn{2}{c}{ Non-smoking room } & Smoking room \\
\hline PM & \multicolumn{2}{c}{ Chamber experiments } \\
nicotine & n.d.-7.2 & $210-450$ \\
3-EP & n.d.-4.1 & $48-100$ \\
UVPM & $1.1-13$ & $9.1-22$ \\
scopoletin & $0.0049-0.12$ & -- \\
\hline \multicolumn{2}{c}{} & Field test \\
\hline PM2.5 & $7.0-12$ & $0.28-0.69$ \\
nicotine & n.d.-0.20 & $86-130$ \\
3-EP & n.d. & $9.2-15$ \\
UVPM & n.d. & $0.88-1.5$ \\
scopoletin & $0.00079-0.0019$ & -- \\
\hline
\end{tabular}


Table 2. Correlation $\left(\mathrm{R}^{2}\right)$ between ETS tracers and $\mathrm{SF}_{6}$ for the chamber experiments.

\begin{tabular}{|c|c|c|c|c|c|c|}
\hline & $\mathrm{SF}_{6}$ & $\mathrm{PM}$ & nicotine & 3-EP & UVPM & scopoletin \\
\hline \multicolumn{7}{|c|}{ Non-smoking room concentrations } \\
\hline $\mathrm{SF}_{6}$ & 1 & - & - & - & - & - \\
\hline PM & 0.99 & 1 & - & - & - & - \\
\hline nicotine & 0.79 & 0.80 & 1 & - & - & - \\
\hline 3-EP & 0.89 & 0.90 & 0.82 & 1 & - & - \\
\hline UVPM & 0.98 & 0.98 & 0.77 & 0.96 & 1 & - \\
\hline scopoletin & 0.89 & 0.90 & 0.82 & 0.73 & 0.81 & 1 \\
\hline \multicolumn{7}{|c|}{ Smoking room concentrations } \\
\hline $\mathrm{SF}_{6}$ & 1 & - & - & - & - & - \\
\hline PM & 0.83 & 1 & - & - & - & - \\
\hline nicotine & 0.12 & 0.06 & 1 & - & - & - \\
\hline 3-EP & 0.20 & 0.08 & 0.92 & 1 & - & - \\
\hline UVPM & - & - & - & - & - & - \\
\hline scopoletin & 0.33 & 0.64 & 0.08 & 0.10 & - & 1 \\
\hline \multicolumn{7}{|c|}{ Exposure ratios } \\
\hline $\mathrm{SF}_{6}$ & 1 & - & - & - & - & - \\
\hline PM & 1.00 & 1 & - & - & - & - \\
\hline nicotine & 0.82 & 0.81 & 1 & - & - & - \\
\hline 3-EP & 0.97 & 0.97 & 0.92 & 1 & - & - \\
\hline UVPM & - & - & - & - & - & - \\
\hline scopoletin & 0.80 & 0.77 & 0.95 & 0.88 & - & 1 \\
\hline
\end{tabular}


Table 3. Predicted smoking room performance for each day of the field test.

\begin{tabular}{ccc}
\hline Day & $\eta_{\text {exh }}(\%)$ & $\mathrm{R}_{\text {ETS }}$ \\
\hline 1 & 98.7 & 80.2 \\
2 & 98.3 & 62.9 \\
3 & 98.4 & 69.0 \\
\hline
\end{tabular}




\section{LIST OF FIGURES}

Figure 1. Experimental chamber. Mixing fans and space heaters not shown in diagram.

Figure 2. Leakage flow from SR to NSR as a function of pressure gradient across given boundary.

Figure 3. Exhaust efficiency, $\eta_{\mathrm{exh}}$, and ETS reduction factor, $\mathrm{R}_{\mathrm{ETS}}$, measured in Experiment Set 3 as a function of pressure gradient between SR and NSR, $\Delta \mathrm{P}_{\mathrm{SR}}$.

Figure 4. Modeled versus measured values of SR exhaust efficiency and ETS reduction factor for 23 chamber tests.

Figure 5. Exposure ratios $\left(=[\mathrm{ETS}]_{\mathrm{NSR}} /[\mathrm{ETS}]_{\mathrm{SR}}\right)$ calculated with $\mathrm{SF}_{6}, 3-\mathrm{EP}, \mathrm{PM}$, scopoletin, and nicotine in the chamber tests. 


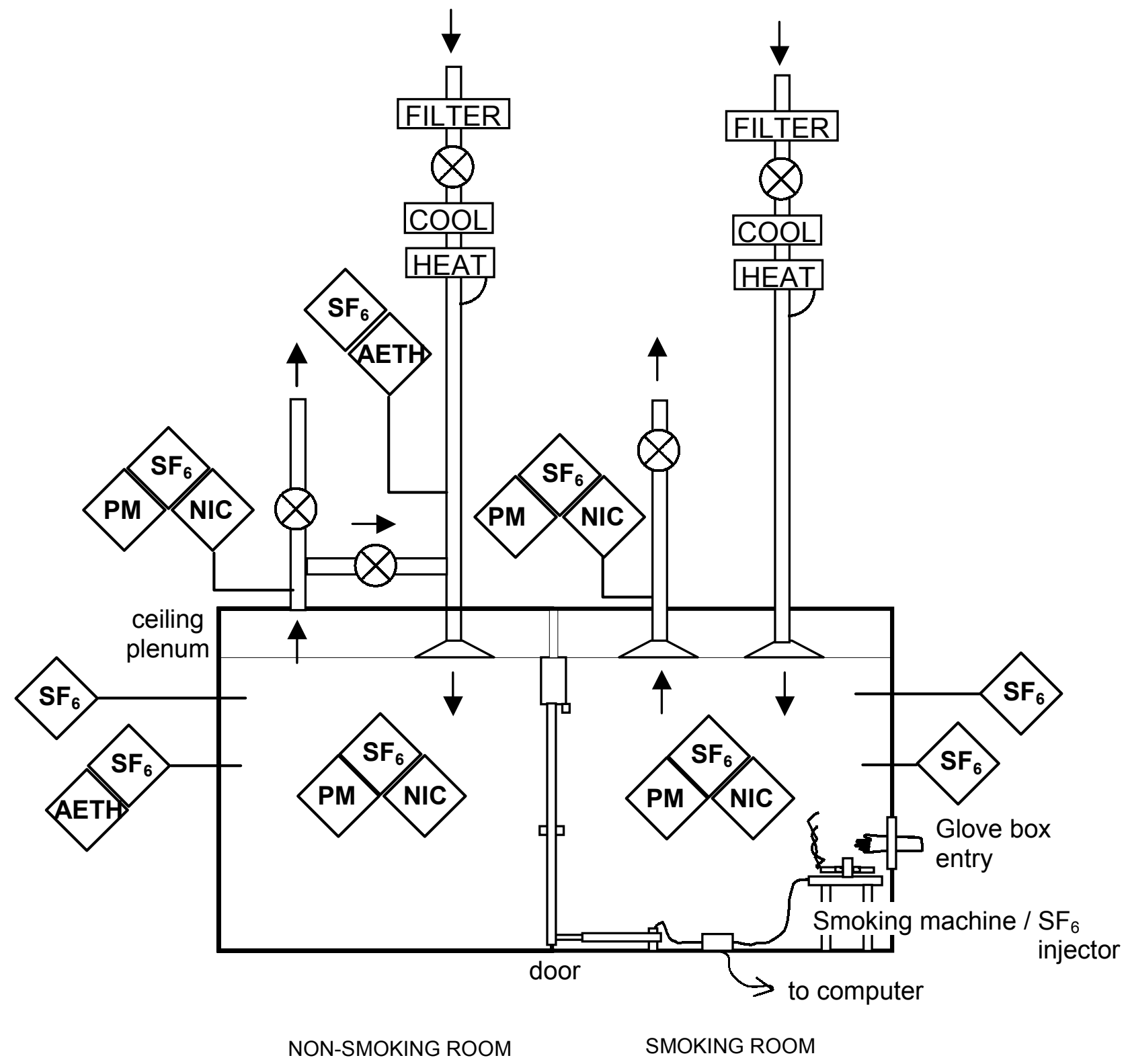

Page 18 of 23 
Figure 1

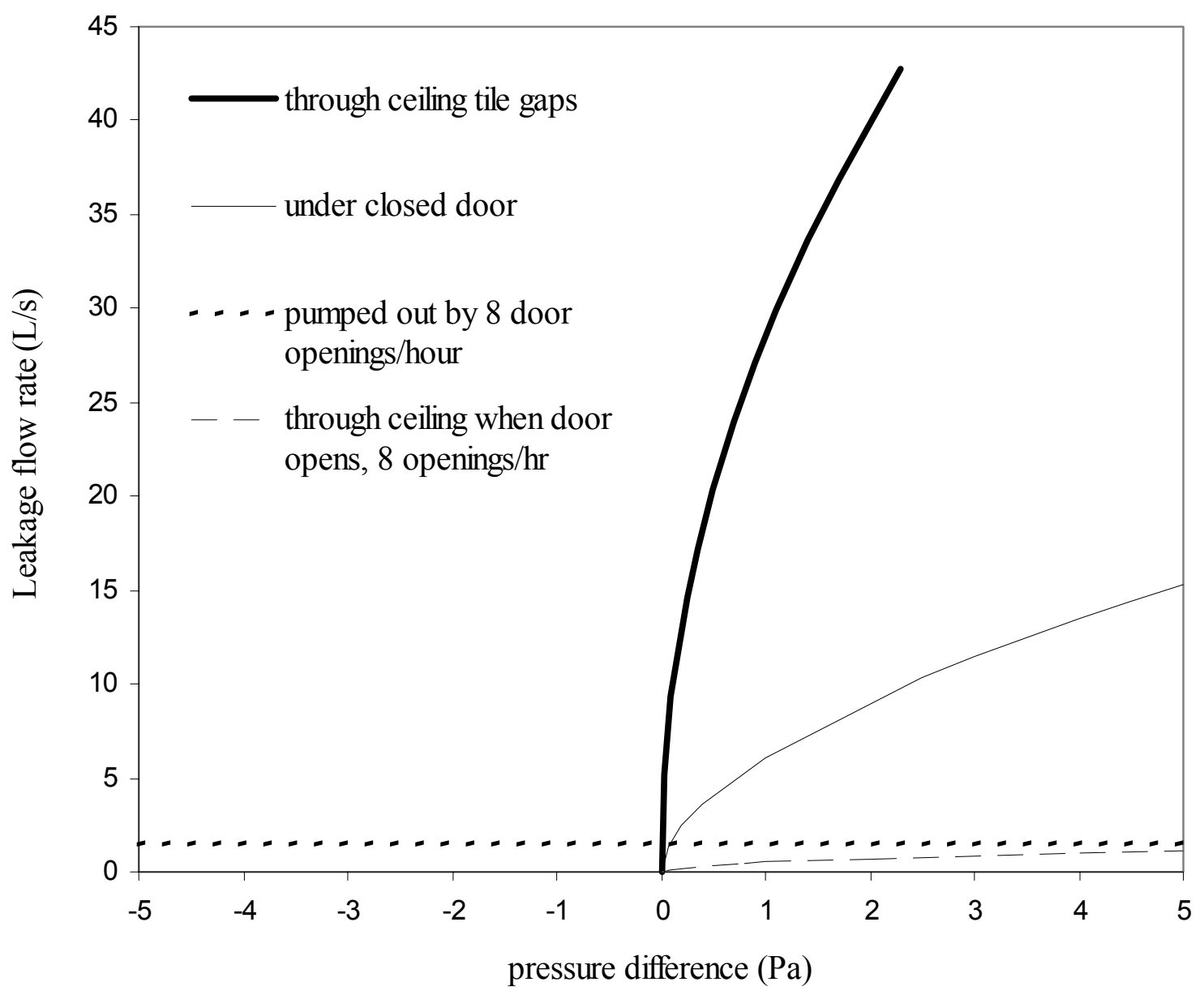


Figure 2

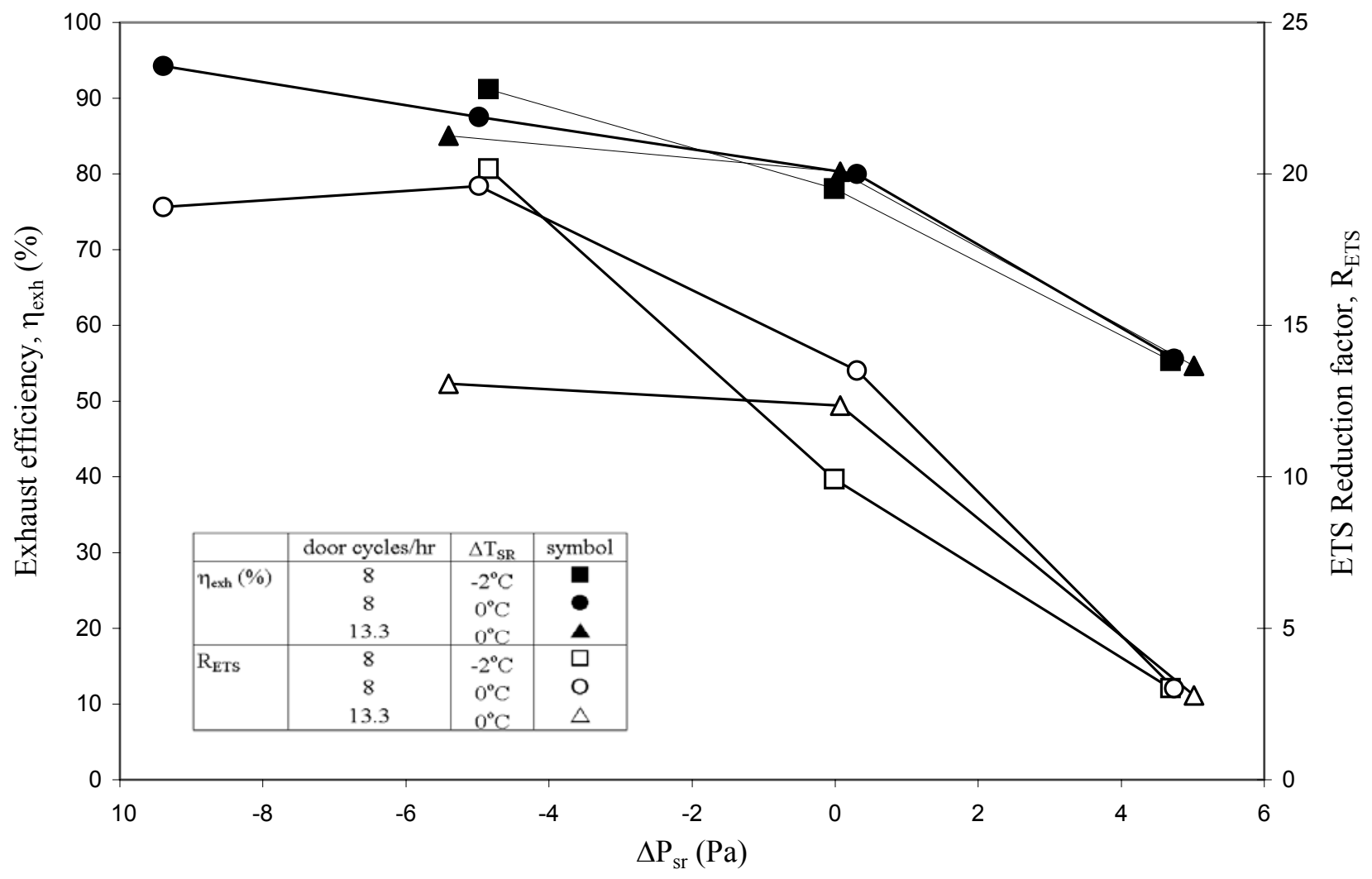


Figure 3

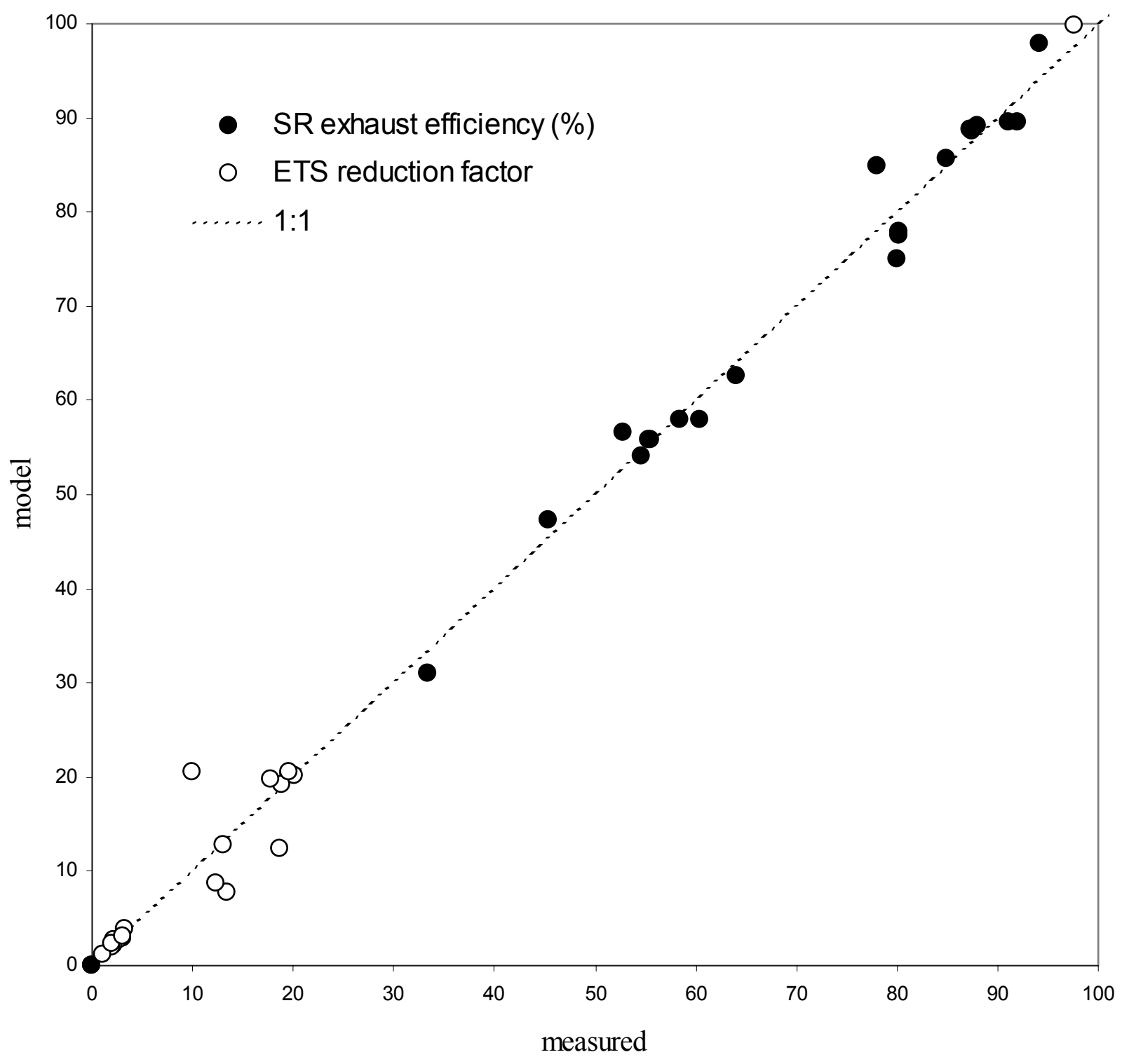

Page 21 of 23 
Figure 4

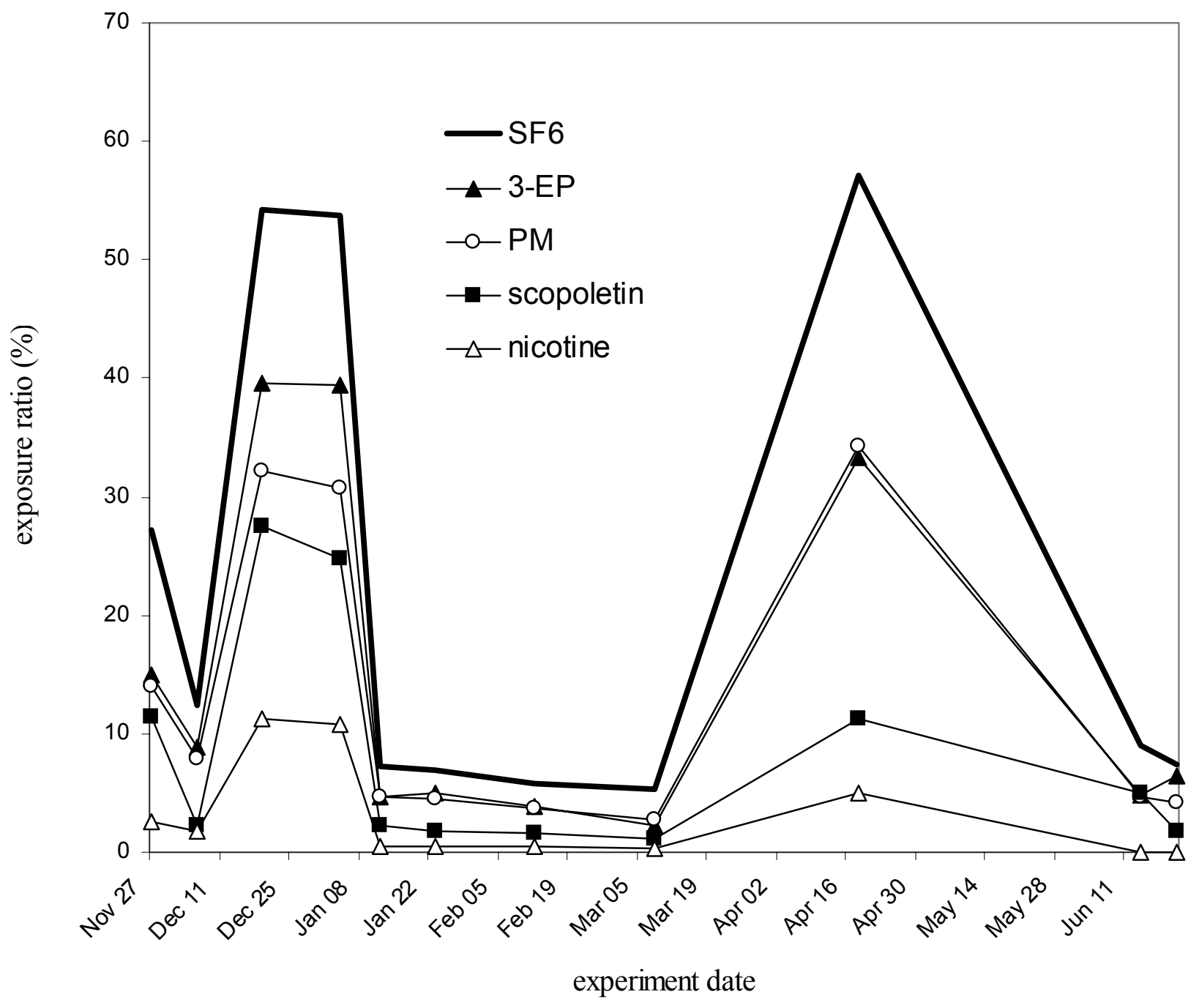

Page 22 of 23 
Figure 5

Page 23 of 23 